\title{
The association between hyperkyphosis and fall incidence among community-dwelling older adults
}

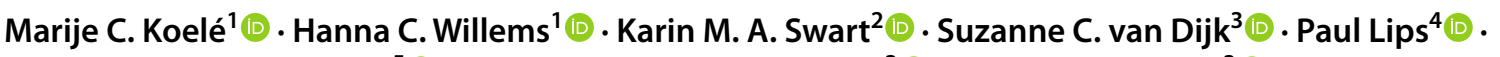 \\ Lisette C. P. G. M. de Groot ${ }^{5}$ (1) - Tischa J. M. van der Cammen ${ }^{3}$ - $\cdot$ M. Carola Zillikens ${ }^{3}$ (D) Natasja M. van Schoor ${ }^{2}$. \\ Nathalie van der Velde ${ }^{1,3}$ (i)
}

Received: 13 February 2021 / Accepted: 25 August 2021 / Published online: 8 September 2021

(c) The Author(s) 2021

\begin{abstract}
Summary Hyperkyphosis, an increased kyphosis angle of the thoracic spine, was associated with a higher fall incidence in the oldest quartile of a large prospective cohort of community-dwelling older adults. Hyperkyphosis could serve as an indicator of an increased fall risk as well as a treatable condition.

Introduction Hyperkyphosis is frequently found in adults aged 65 years and older and may be associated with falls. We aimed to investigate prospectively in community-dwelling older adults whether hyperkyphosis or change in the kyphosis angle is associated with fall incidence.

Methods. Community-dwelling older adults ( $n=1220$, mean age $72.9 \pm 5.7$ years) reported falls weekly over 2 years. We measured thoracic kyphosis through the Cobb angle between the fourth and 12th thoracic vertebra on DXA-based vertebral fracture assessments and defined hyperkyphosis as a Cobb angle $\geq 50^{\circ}$. The change in the Cobb angle during follow-up was dichotomized $\left(<5\right.$ or $\left.\geq 5^{\circ}\right)$. Through multifactorial regression analysis, we investigated the association between the kyphosis angle and falls.

Results Hyperkyphosis was present in $15 \%$ of the participants. During follow-up, $48 \%$ of the participants fell at least once. In the total study population, hyperkyphosis was not associated with the number of falls (adjusted IRR 1.12, 95\% CI 0.91-1.39). We observed effect modification by age $(p=0.002)$. In the oldest quartile, aged 77 years and older, hyperkyphosis was prospectively associated with a higher number of falls (adjusted IRR 1.67, 95\% CI 1.14-2.45). Change in the kyphosis angle was not associated with fall incidence.

Conclusions Hyperkyphosis was associated with a higher fall incidence in the oldest quartile of a large prospective cohort of community-dwelling older adults. Because hyperkyphosis is a partially reversible condition, we recommend investigating whether hyperkyphosis is one of the causes of falls and whether a decrease in the kyphosis angle may contribute to fall prevention.
\end{abstract}

Keywords Kyphosis $\cdot$ Falls $\cdot$ Fall incidence

Nathalie van der Velde

n.vandervelde@amsterdamumc.nl

1 Department of Internal Medicine, Division of Geriatrics, Amsterdam Public Health Research Institute, Amsterdam UMC, Academic Medical Centre Amsterdam, Meibergdreef 9, 1105 AZ Amsterdam, The Netherlands

2 Department of Epidemiology and Biostatistics, Amsterdam Public Health Research Institute, Amsterdam UMC, Vrije Universiteit Amsterdam, van der Boechorststraat 7, 1081 BT Amsterdam, The Netherlands
3 Section of Geriatrics, Department of Internal Medicine, Erasmus MC, University Medical Center Rotterdam, P.O. Box 2040, 3000 CA Rotterdam, The Netherlands

4 Department of Internal Medicine, Endocrine Section, Amsterdam Public Health Research Institute, Amsterdam UMC, Vrije Universiteit Amsterdam, van der Boechorststraat 7, 1081 BT Amsterdam, The Netherlands

5 Division of Human Nutrition, Wageningen University, P.O. Box 8129, 6700 EV Wageningen, The Netherlands 


\section{Introduction}

The incidence of falls is high among older adults: one out of three adults aged 65 years and older experiences one or more falls annually [1-3]. Serious injuries occur in one out of five fall incidents [3], with negative consequences for both the individual patient and society. In the individual patient, downregulation of activities due to fear of falling causes deconditioning [4, 5]. Deconditioning increases fall risk, resulting in a lower quality of life $[6,7]$. Furthermore, patients live three times more often in a nursing home after hospitalization due to fall-related injury than to a non-fall-related reason [6]. Society bears the high medical costs of hospitalization and other medical care needed after a fall incident $[7,8]$. As fall rates and accompanying medical costs have been rising worldwide over the past decade [7-9], identifying fall risk factors is important in order to minimize the number of fall incidents and thereby their negative consequences.

One of the most important fall risk factors is a balance disorder [10]. Balance may be influenced by thoracic hyperkyphosis, an excessive curvature of the thoracic spine. Hyperkyphosis may shift the center of mass of the body forward if compensation in the lumbar spine and hip region is not sufficient and thereby cause gait disorders and disruption of balance [11-13]. Hyperkyphosis is frequently found in older adults [14]. However, conflicting results regarding the association between hyperkyphosis and fall risk are reported [15-22]. The only large prospective study on this association recently showed that in older men a larger kyphosis angle, measured with the blocks method, was associated to fall risk ( $R R=1.12,95 \%$ $\mathrm{CI}=1.06,1.18$ ), yet a larger Cobb angle was not associated to fall risk [23]. The Cobb angle, the angle between two thoracic vertebra on a lateral radiograph in standing position [24], has been used extensively in literature to measure the kyphosis angle [14]. More prospective studies are warranted in both men and women using the Cobb angle, to investigate whether a larger kyphosis angle is associated with fall incidents over time.

We hypothesized that hyperkyphosis, measured with the Cobb angle (Fig. 1), will be prospectively associated to an increased fall incidence in a large cohort of older adults.

Whether change in kyphosis over time influences fall risk has not yet been investigated. Change in the kyphosis angle over time may alter the body's center of mass that could negatively impact balance and increase fall risk. Adapting to the change in the kyphosis angle may increase fall risk. We hypothesized therefore that change in the kyphosis angle over time will be associated to an increased fall risk.

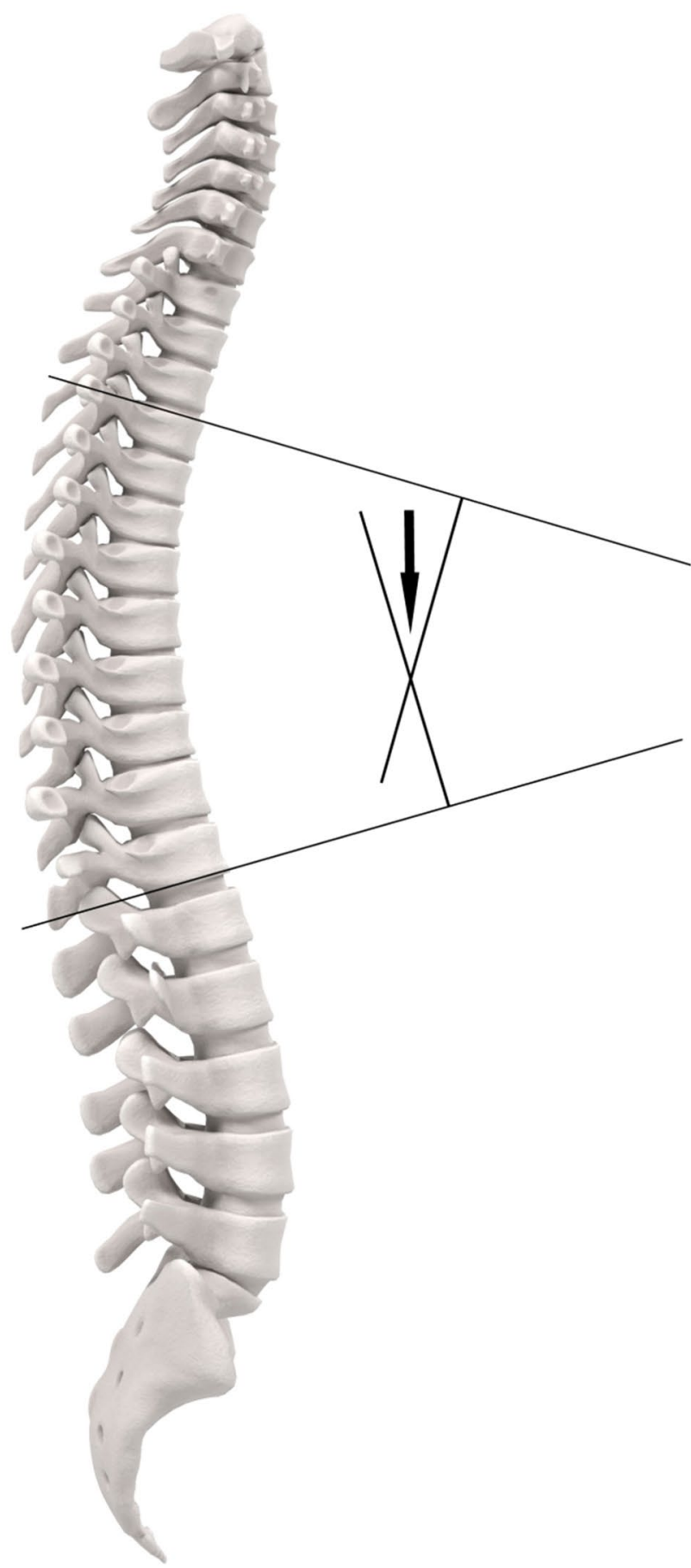

Fig. 1 Cobb angle

\section{Methods}

\section{Participants}

The current study was performed within the sub-sample of the B-PROOF study in which a dual-energy X-ray 
assessment (DXA) was available $(n=1220)$. Only participants included in two of the three study centers underwent a DXA, because a DXA scanner was only present in these two study centers. The B-PROOF (B-vitamins for the Prevention of Osteoporotic Fractures) study is a multi-center randomized placebo-controlled double-blind intervention study aimed at investigating whether vitamin $B_{12}$ and folic acid supplementation reduces osteoporotic fracture incidence in older individuals with an elevated homocysteine level. Inhabitants of the area of the research centers in the Netherlands were invited by mail to participate if they were 65 years or older. Participants were included from August 2008 until March 2011 if their plasma homocysteine level was $\geq 12 \mu \mathrm{mol} / \mathrm{L}$. Renal function influences homocysteine levels. Therefore, participants were included if they had sufficient renal function (serum creatinine concentration $\leq 150 \mu \mathrm{mol} / \mathrm{L}$ ). They were excluded if they reported malignancies in the past 5 years and if they were bedridden or wheelchair bound [25]. Because the supplementation of vitamin $\mathrm{B}_{12}$ and folic acid had no effect on osteoporotic fractures, fall incidence, or physical performance [26], we treated the study population of the original trial as a cohort in our current study. Informed consent was obtained from all individual participants included in the study.

\section{Cobb angle}

The Cobb angle was first described to quantify scoliosis. By modifying the direction of radiographic imaging from anterior-posterior to lateral projection, the Cobb angle became useful to assess kyphosis angles [22]. Numerous kyphosis measurement methods have been used to quantify the kyphosis angle, both in standing and recumbent position [23, 27-29]. The Cobb angle is currently considered to be the gold standard kyphosis measurement when measured on standing radiographic images [14]. We measured the Cobb angle on the DXA-based vertebral fracture assessment (VFA), made in the recumbent position. In several studies, the Cobb angle has been applied in recumbent position [29-31]. Kado et al. and Tran et al. showed a reasonable correlation between the Cobb angle in recumbent position and kyphosis, measured in standing position (ICC 0.65-0.68), and a reasonable correlation (ICC 0.68) between two kyphosis measurement methods in recumbent position [32]. Yet this correlation may be lower with increasing kyphosis angles, as a correlation of 0.44 was reported in hyperkyphotic participants (Cobb angle $\geq 50^{\circ}$ ) [33]. We defined hyperkyphosis as a Cobb angle of $\geq 50^{\circ}$ in order to compare our results with prior research [18, 27].

Two researchers (SK and $\mathrm{IH}$ ) measured the Cobb angle independently. If the difference between the two measurements of the Cobb angle was less than $10^{\circ}$, we used the mean value. A third researcher (HW) remeasured the Cobb angle if the difference between the measurements was $10^{\circ}$ or more or if the Cobb angle was judged to be more than $50^{\circ}$ by one researcher and less than $50^{\circ}$ by the other researcher. The third researcher remeasured 101 Cobb angles out of a total of 2,322 DXA scans (Cohen's kappa 0.96): 53 because of a difference of more than $10^{\circ}$ between the initial measurements of the two investigators, and the remaining 48 were remeasured because of different categorization of hyperkyphosis versus a normal kyphosis angle. Based on consensus, two researchers (HW and MK) decided the value of the final Cobb angle. In 1,102 participants, a DXA performed after 2 years of follow-up was available.

\section{Falls}

A fall was defined as "an unintentional change in position resulting in coming to rest at a lower level or on the ground." Participants recorded falls prospectively on a research calendar every week. They returned the research calendar every 3 months. Participants were followed for 2 years after the baseline measurements. The primary outcome measure was the number of falls during follow-up [34].

\section{Covariables}

We obtained age, gender, educational level, current alcohol intake, current or former smoking, use of a walking aid, medical history, and information on use of a walking aid and current medication use through structured questionnaires at baseline. We measured height, weight, and 25-hydroxyvitamin-D concentration. Participants performed a timed tandem-stance test to assess balance. We measured for a maximum of $10 \mathrm{~s}$ how long participants were able to stand with one foot directly in front of the other with their eyes opened. Because of a ceiling effect, with 909 of the participants (75\%) successfully standing in a tandem stance during the maximum duration of $10 \mathrm{~s}$, we used categorized scores of the tandem-stance test. Scores ranged from 0 to 4 points $(4,10 \mathrm{~s} ; 2,4-9 \mathrm{~s} ; 0,4 \mathrm{~s}$ or less) and were categorized [35]. Hand-grip strength was measured with a strain-gauged dynamometer (Takei, TKK 5401, Takei Scientific Instruments Co. Ltd., Japan).

\section{Statistical analysis}

We compared baseline characteristics of the hyperkyphotic and the non-hyperkyphotic through a chi-square test for categorical and an independent Student's $t$-test for continuous data. We used nonparametric tests if the distribution was skewed.

We performed a negative binomial regression analysis to test the association between number of falls and both 
hyperkyphosis and change in the kyphosis angle. Based on interrater reliability and intrarater reliability in the literature [36, 37], and our own cohorts (data not published) of 3.2-4.5 , we interpreted an increase in the Cobb angle of at least $5^{\circ}$ during the follow-up as the minimal detectable difference. Five degrees of change has been shown to be associated with a decrease in physical performance and may therefore be clinically relevant [38]. We dichotomized change in the Cobb angle during follow-up to change $\left(\geq 5^{\circ}\right)$ or no change $\left(<5^{\circ}\right)$.

The initial model only included hyperkyphosis and the number of falls. In this model, we tested for interaction with gender, because previous studies reported effect modification regarding the association between hyperkyphosis and fall risk [17, 21]. Based on a priori decisions, we also tested for interaction with age (oldest quartile vs. youngest 3 quartiles) and study center. If the $p$-value of interaction was 0.10 or below, we performed stratified analyses. In case of stratification, we compared relevant baseline characteristics between groups.

We tested for potential confounders by adding covariables separately to the initial model. If there was a change of $\geq 10 \%$ of the regression coefficient when adding a separate covariable, the covariable was considered to be a confounder and added to the adjusted model. We tested for confounding by age, gender, and study center if these variables were not effect modifiers. Furthermore, we tested for confounding by smoking, alcohol use, cardiovascular comorbidity, number of medications, use of a walking aid, and treatment allocation in the original trial.

In case of a statistically significant association between hyperkyphosis and number of falls, we assessed whether balance, hand-grip strength, and vitamin D concentration mediated this association. Balance is a potential mediator, because hyperkyphosis causes disruptions of balance and may therefore increase fall risk [11]. Multiple studies show an association between hyperkyphosis and decreased physical performance and even impairments in performance of activities of daily living [27], which may lead to physical inactivity and less exposure to sunlight. Through this pathway, muscle strength and vitamin D may also mediate the association between hyperkyphosis and falls.

We added these variables separately to the adjusted models, and if the incident rate ratio changed $10 \%$ or more, we considered the variable a mediator. Because osteoporosis is one of the causes of hyperkyphosis, we considered osteoporosis and the presence of one or more fractures as overlapping factors with hyperkyphosis. To avoid overadjustment, we did not adjust for these variables. The level of significance was set at $\alpha=0.05$. We performed statistical analyses with SPSS software, version 21.0.

\section{Results}

Baseline characteristics are listed in Table 1. The mean age of the 1,220 participants was $72.9 \pm 5.7$ years. One-third of the participants reported a fall in the year before inclusion. During follow-up, $48 \%$ of participants had experienced one or more falls, and $25 \%$ were recurrent fallers. The median number of falls was one (interquartile range 0-2) in hyperkyphotic participants and zero (interquartile range $0-1$ ) in participants with a normal kyphosis angle. Hyperkyphosis was present in $15 \%$ of the participants. The mean Cobb angle was $37.0^{\circ} \pm 11.9^{\circ}$ in the total cohort, with a mean Cobb angle of $56.6^{\circ} \pm 6.4^{\circ}$ in hyperkyphotic participants and $33.5^{\circ} \pm 8.9^{\circ}$ in participants with a normal kyphosis angle. Participants with hyperkyphosis were older and more often female. Furthermore, they used a walking aid more often, had less hand-grip strength, and had a lower score on the balance test. Consistent with the fact that osteoporotic vertebral fractures cause hyperkyphosis, hyperkyphotic participants more often had vertebral fractures at baseline and clinical fractures after the age of 50 years. Although physical activity level was similar in both groups, the mean maximal handgrip strength was lower for the hyperkyphotic group, which also more often had abnormal results in the balance test. In $22 \%(n=240)$ of the participants with a VFA at follow-up, the increase in the Cobb angle was $5^{\circ}$ or more. The mean change in the Cobb angle was $0.46^{\circ} \pm 5.7^{\circ}$.

Table 2 shows the association between falls and both hyperkyphosis at baseline and change in the kyphosis angle during follow-up. In the analyses regarding the association between hyperkyphosis and number of falls only, we observed effect modification by age $(p=0.002)$. We did not observe effect modification by gender or study center in any of the analyses.

In the adjusted analyses, hyperkyphosis was not associated with the number of falls, with an incident rate ratio (IRR) of 1.12 (95\% CI 0.91-1.39, $p=0.291$ ). Hyperkyphosis was significantly associated with a higher number of falls during follow-up in the oldest quartile of our cohort, aged 77 and older (IRR 1.53, 95\% CI 1.10-2.12, $p=0.012$ ). The oldest quartile more often had cardiovascular comorbidity, used more medications, and used a walking aid more often (all $p<0.001$; Table 3). We tested for potential confounding by gender, smoking, alcohol use, treatment allocation, study center, use of a walking aid, cardiovascular comorbidity, and number of medications. Although the oldest quartile used a walking aid more often than the three younger quartiles, use of a walking aid was not a confounder. The covariables gender, smoking, alcohol use, treatment allocation, and study center were also no confounders. Only gender, cardiovascular comorbidity, and number of medications changed the regression coefficient $\geq 10 \%$ and were added to the model. 
Table 1 Baseline characteristics

\begin{tabular}{|c|c|c|c|}
\hline Characteristic & Hyperkyphosis $(n=188)$ & $\begin{array}{l}\text { No hyperkyphosis } \\
(n=1032)\end{array}$ & $p$ \\
\hline Age (years, SD) & $74.7 \pm 6.3$ & $72.5 \pm 5.5$ & $<.001$ \\
\hline Female $(n, \%)$ & $128(68 \%)$ & $462(45 \%)$ & $<.001$ \\
\hline Education level $(n, \%)$ & & & 0.27 \\
\hline Low & $111(59 \%)$ & $544(53 \%)$ & \\
\hline Intermediate & $35(19 \%)$ & $209(20 \%)$ & \\
\hline High & $42(22 \%)$ & $277(27 \%)$ & \\
\hline Current or former smoker $(n, \%)$ & $105(56 \%)$ & $707(69 \%)$ & 0.001 \\
\hline \multicolumn{4}{|l|}{ Alcohol use } \\
\hline$\geq 1$ unit per day $(n, \%)$ & $49(26 \%)$ & $388(38 \%)$ & 0.002 \\
\hline Cardiovascular comorbidity $(n, \%)$ & $48(27 \%)$ & $295(31 \%)$ & 0.42 \\
\hline Number of medications (median, IQR) & $2.5(1.0-4.0)$ & $3.0(1.0-5.0)$ & 0.89 \\
\hline BMI $\left[\mathrm{kg} / \mathrm{m}^{2}\right]$ (mean, SD) & $27.0 \pm 3.8$ & $27.0 \pm 3.9$ & 0.83 \\
\hline MMSE-score (median, IQR) & $28(27-29)$ & $28(27-29)$ & 0.98 \\
\hline GDS-15-score (median, IQR) & $1(0-2)$ & $1(0-2)$ & 0.96 \\
\hline 25-OH-vitamin D [ng/mL] (mean, SD) & $20.7 \pm 8.8$ & $22.3 \pm 9.6$ & 0.030 \\
\hline \multicolumn{4}{|l|}{ Vertebral fractures } \\
\hline$\geq 2$ fractures present $(n, \%)$ & $20(11 \%)$ & $66(6 \%)$ & 0.034 \\
\hline Fracture after the age of $50(n, \%)$ & $59(31 \%)$ & $228(22 \%)$ & 0.006 \\
\hline Use of walking aid $(n, \%)$ & $23(12 \%)$ & $66(6 \%)$ & 0.005 \\
\hline Physical activity [min/day] (mean, SD) & $165(102)$ & 160 (106) & 0.52 \\
\hline Hand-grip strength (mean, SD) & $29.0 \pm 9.2$ & $33.8 \pm 10.2$ & $<.001$ \\
\hline Balance test abnormal $(n, \%)$ & $75(40 \%)$ & $258(25 \%)$ & $<.001$ \\
\hline Cobb angle & $56.6^{\circ} \pm 6.4^{\circ}$ & $33.5^{\circ} \pm 8.9^{\circ}$ & $<.001$ \\
\hline Participants with $\geq 1$ incident falls $(n, \%)$ & $97(52 \%)$ & $492(48 \%)$ & 0.322 \\
\hline
\end{tabular}

Table 2 Results of the negative binomial regression analyses of the association between the number of falls and both hyperkyphosis and change in the kyphosis angle
Table 3 Differences in baseline characteristics between the oldest quartile, aged 77 years and older, and the youngest 3 quartiles

\begin{tabular}{lllll}
\hline & Model 1 ${ }^{\mathrm{a}}$ Ratio, 95\% CI & $p$ & Model 2 Ratio, 95\% CI & $p$ \\
\hline Hyperkyphosis & IRR 1.15(0.94-1.42) & 0.182 & IRR 1.12 (0.90-1.40) & 0.31 \\
Oldest quartile & IRR 1.53 (1.10-2.12) & 0.012 & IRR 1.67 (1.14-2.45) & 0.008 \\
Youngest 3 quartiles & IRR 0.87 (0.62-1.71) & 0.925 & IRR 0.91 $(0.68-1.23)^{\mathrm{b}}$ & 0.55 \\
Change of kyphosis & IRR 1.01 (0.98-1.03) & 0.654 & IRR 1.00 (0.98-1.03) & 0.83 \\
\hline
\end{tabular}

${ }^{a}$ Unadjusted

${ }^{\mathrm{b}}$ Corrected for gender, cardiovascular comorbidity, and number of medications

${ }^{\mathrm{C}}$ Corrected for age and gender

\begin{tabular}{llll}
\hline Characteristic & $\begin{array}{l}\text { Oldest quartile } \\
(n=314)\end{array}$ & $\begin{array}{l}\text { Youngest three quartiles } \\
(n=906)\end{array}$ & $p$ \\
\hline Age (years, SD) & $80.6 \pm 3.5$ & $70.2 \pm 3.3$ & $<.001$ \\
Female $(n, \%)$ & $149(48 \%)$ & $441(49 \%)$ & 0.71 \\
Cardiovascular comorbidity $(n, \%)$ & $102(32 \%)$ & $241(27 \%)$ & 0.001 \\
Number of medications (median, IQR) & $3(1-5)$ & $2(1-4)$ & $<.001$ \\
Use of walking aid $(n, \%)$ & $59(19 \%)$ & $30(3 \%)$ & $<.001$ \\
Physical activity [min/day] (mean, SD) & $140(86)$ & $168(110)$ & $<.001$ \\
Hand-grip strength (mean, SD) & $29.5 \pm 9.1$ & $34.3 \pm 10.3$ & $<.001$ \\
Balance test abnormal $(n, \%)$ & $92(29 \%)$ & $242(27 \%)$ & 0.38 \\
\hline
\end{tabular}


In the adjusted analyses, the association persisted (IRR 1.67, 95\% CI 1.14-2.45, $p=0.008$ ).

Balance, vitamin D concentration, and hand-grip strength did not mediate the association between hyperkyphosis and number of falls. Change in the kyphosis angle during the 2 years of follow-up was not associated with number of falls in the unadjusted and adjusted model (adjusted IRR 0.96, 95\% CI 0.79-1.17, $p=0.689$ ).

\section{Discussion}

Hyperkyphosis was prospectively associated with a higher number of falls in the oldest quartile, aged 77 years and older, in a cohort of Dutch community-dwelling older adults. Change in the kyphosis angle was not associated with the number of falls during follow-up.

Most cross-sectional and in particular the 2 small prospective cohort studies reported a higher fall risk for hyperkyphotic participants [20, 23]. In our study, a significant association between hyperkyphosis and falls was only found in the oldest quartile, with a mean age of 80 years, a mean number of medications of 4 , and cardiovascular comorbidity present in 32\% (see supplement table S1). This is in concordance with current literature as both prospective studies assessed a comparable population. The cohort of van der Jagt-Willems consisted of geriatric outpatients with a mean age of 79 years, an average number of 6 medications, and an average Charlson Comorbidity Score of 1.3. McDanielsDavidson included community-dwelling older adults as was the case in our cohort, though with a higher mean age of 78 years, $65 \%$ having more than 3 chronic conditions and an average number of 4 medications. This study and previous literature show that hyperkyphosis appears to form a fall risk factor in particularly the oldest age group, who have more comorbidities negatively affecting the compensatory mechanisms to prevent falls [11, 18, 19]. Generally, the number of fall risk factors increases with age. Among older adults, hyperkyphosis adds to a higher number of other fall risk factors and a decreased capability to prevent falls, resulting in an increased absolute fall risk.

Against the expectation, increase of the kyphosis angle was not associated with the number of falls during 2 years of follow-up. This may be explained by the low number of participants $(n=240)$ with an increase of the Cobb angle of $\geq 5^{\circ}$. Mean change of the Cobb angle in this cohort was $0.46^{\circ} \pm 5.7^{\circ}$. This is a small change compared to two previous studies, describing an increase of the Cobb angle $2.6^{\circ}$ in 3 years and $7^{\circ}$ in 15 years and 3.9 in 4 years $[38,39]$. The follow-up duration of our study may have been too short to investigate this hypothesis.

We investigated potential contributory factors in the association between hyperkyphosis and falls. Previous literature showed that hyperkyphosis may disrupt balance [11] and, because balance disorders are a major fall risk factor, may therefore enhance fall risk. The current cohort study does not support this hypothesis, because performance on the balance test did not mediate the association between hyperkyphosis and number of falls. This is in line with other studies, reporting no association between hyperkyphosis and balance [13, 27, 40].

Apparently, literature is contradicting on the association between hyperkyphosis and balance. Yet, rather uniformly, sagittal inclination of the spine as a whole and the lumbar lordosis angle have been shown to be associated to impaired balance [13, 41] and a higher fall risk [18, 19, 41-43]. The Cobb angle is not always correlated to inclination of the total spine, as shown by Demarteau et al. and Katzman et al. in community-dwelling older adults $[12,13]$.

This may indicate that hyperkyphosis indeed influences balance and thereby fall risk, if it leads to a forward shift of the center of mass which cannot be compensated in the lumbosacral and hip region. The older adults participating in this study may have had enough ability to compensate a potential forward shift of the center of mass.

Another cause for not finding an effect of balance in our cohort may be that the sensitivity of the tandem-stance test may be limited. Using a more extensive balance test, such as the Berg Balance Scale, might lead to different results.

Another explanation for the higher fall incidence in older adults with hyperkyphosis may be muscle weakness. Muscle strength decreases with aging, and lower back-extensormuscle strength and lower hand-grip strength is associated with a larger kyphosis angle [44] as well as with increased fall risk. However, although the adults aged 77 years and older had significantly lower hand-grip strength at baseline than the younger adults in our cohort (Table 3), we found no confounding or mediation by grip strength. Yet, in this study, we only measured hand-grip strength, which may be a suboptimal measure for muscle strength associated with hyperkyphosis compared to back-extensor-muscle strength.

The use of a walking aid may have influenced fall risk. Higher as well as lower fall risks among walking aid users have been described in literature. Twelve percent of the participants with hyperkyphosis reported using a walking aid versus $6 \%$ of the participants with a normal kyphosis angle. The use of a walking aid was no confounder regarding the association between hyperkyphosis and fall incidence. We have no evidence that the type of walking aid influenced the association between hyperkyphosis and the number of falls in this cohort.

Our cohort study has several strengths, including the prospective design with 2 years of prospective follow-up of the fall incidents and the large sample size. Furthermore, this study is the first to investigate the association between change in the kyphosis angle during follow-up and the fall incidence in older adults. Thus, we were able to detect 
potential temporary effects of a change in the kyphosis angle on the fall risk.

However, there are three limitations. First, we limited our analyses to the 1,220 participants of the cohort in whom a DXA was performed. The decision of whether a participant received a DXA scan was merely based on the availability of a DXA scanner in the study center. Potentially, we could have underestimated the association between hyperkyphosis and fall incidence by selecting participants who were fit enough to undergo the DXA scans. Secondly, the traditional gold standard kyphosis measurement is the Cobb angle, measured in standing position [14]. In our study, DEXA-based vertebral fracture assessments, made in recumbent position, were used. The posture of the participant during kyphosis measurement may influence the Cobb angle. The supine position eliminates the effects of gravity and the muscles and ligaments of the back, and the Cobb angle is expected to be smaller than in standing position, particularly among those with a greater degree of kyphosis [33].

Therefore, the use of DEXA-based vertebral fracture assessments, made in recumbent position, may have led to underestimation of the Cobb angle and the prevalence of hyperkyphosis in this cohort due to misclassification. The prevalence of hyperkyphosis in our study is indeed lower than in previous literature, in which prevalence ranges between 20 and $40 \%$ [14]. This may have led to underestimation of the association between hyperkyphosis and falls. Thirdly, all participants had a slightly elevated homocysteine level (median 14.4 (IQR 13.0-16.6) $\mu \mathrm{mol} / \mathrm{L}$ ), which may limit generalizability of study results. Nevertheless, we have no reason to assume a different association between hyperkyphosis and falls in normo-homocysteinic older adults compared to hyperhomocysteinic older adults, because the literature has reported no such difference. Additionally, in the general population, elevated homocysteine concentrations ( $\geq 15 \mu \mathrm{mol} / \mathrm{L})$ are prevalent in 30 to $50 \%$ people aged 65 years and older [25] Treatment of the elevated homocysteine level did not affect fall risk or physical performance [26] In addition, treatment allocation was not a confounder in the analyses. Therefore, we think the homocysteine level is unlikely to have influenced the association between hyperkyphosis and fall incidence.

In conclusion, hyperkyphosis was associated with a higher number of falls in the adults aged 77 years and older of this first large prospective study in community-dwelling older adults. This association is of particular interest because hyperkyphosis is partially reversible [45]. Hyperkyphosis could serve as an indicator of an increased fall risk as well as a treatable condition in order to diminish the fall risk of an older adult with hyperkyphosis. Therefore, we recommend that future research investigate whether hyperkyphosis is one of the causes of falls and whether a decrease in the kyphosis angle contributes to fall prevention.

Supplementary Information The online version contains supplementary material available at https://doi.org/10.1007/s00198-021-06136-6.

Acknowledgements We thank the participants of the B-PROOF study for their enthusiasm and cooperation. We thank Anke Enneman and Annelies Ham for their contributions to the design of the study and the collection of the data. We also thank Sandra Smits, Jopie Sluimer, Ans Nicolaas, Nicolette Pliester and Jos Burcksen for their contributions to the collection of the data and their advises and Iris Harmsen and Simone Kwakman-Brinkkemper for scoring the Cobb angle of all participants.

Funding This research received no specific grant from any funding agency in the public, commercial, or not-for-profit sectors. The original B-PROOF trial is supported and funded by The Netherlands Organization for Health Research and Development (ZonMw, Grant 6130.0031), The Hague; unrestricted grant from NZO (Dutch Dairy Association), Zoetermeer; Orthica, Almere; NCHA (Netherlands Consortium Healthy Ageing), Leiden/Rotterdam; Ministry of Economic Affairs, Agriculture and Innovation (project KB-15-004-003), The Hague; Wageningen University, Wageningen; VUmc, Amsterdam; Erasmus Medical Center, Rotterdam.

Data availability Raw data were generated at the Amsterdam UMC, location AMC. Derived data supporting the findings of this study are available from the corresponding author $(\mathrm{NvdV})$ on request.

Code availability Not applicable.

\section{Declarations}

Ethics approval All procedures performed in studies involving human participants were in accordance with the ethical standards of the institutional and/or national research committee and with the 1964 Helsinki declaration and its later amendments or comparable ethical standards. The Medical Ethics Committee of both study centers approved the study protocol. All participants gave written informed consent.

Consent to participate. Informed consent was obtained from all individual participants included in the study.

Consent for publication. Informed consent was obtained from all individual participants included in the study.

\section{Conflict of interest None.}

Open Access This article is licensed under a Creative Commons Attribution-NonCommercial 4.0 International License, which permits any non-commercial use, sharing, adaptation, distribution and reproduction in any medium or format, as long as you give appropriate credit to the original author(s) and the source, provide a link to the Creative Commons licence, and indicate if changes were made. The images or other third party material in this article are included in the article's Creative Commons licence, unless indicated otherwise in a credit line to the material. If material is not included in the article's Creative Commons licence and your intended use is not permitted by statutory regulation or exceeds the permitted use, you will need to obtain permission directly from the copyright holder. To view a copy of this licence, visit http://creativecommons.org/licenses/by-nc/4.0/. 


\section{References}

1. Bergen G, Stevens MR, Burns ER (2016) Falls and fall injuries among adults aged $>/=65$ years - United States, 2014. MMWR Morb Mortal Wkly Rep 65(37):993-998. https://doi.org/10. 15585/mmwr.mm6537a2

2. Hopewell S, Adedire O, Copsey BJ, Boniface GJ, Sherrington C, Clemson L et al (2018) Multifactorial and multiple component interventions for preventing falls in older people living in the community. Cochrane Database Systematic Reviews. 7:Cd012221. https://doi.org/10.1002/14651858.CD012221.pub2

3. CDC, Home and Recreational Safety, Older Adult Falls. Available at: https://www.cdc.gov/homeandrecreationalsafety/falls/ adultfalls.html. Accessed 14 Feb 2020

4. Jefferis BJ, Iliffe S, Kendrick D, Kerse N, Trost S, Lennon LT et al (2014) How are falls and fear of falling associated with objectively measured physical activity in a cohort of communitydwelling older men? BMC Geriatr 14:114. https://doi.org/10. 1186/1471-2318-14-114

5. Patil R, Uusi-Rasi K, Kannus P, Karinkanta S, Sievanen H (2014) Concern about falling in older women with a history of falls: associations with health, functional ability, physical activity and quality of life. Gerontology 60(1):22-30. https://doi.org/10.1159/ 000354335

6. Gill TM, Murphy TE, Gahbauer EA, Allore HG (2013) Association of injurious falls with disability outcomes and nursing home admissions in community-living older persons. Am J Epidemiol 178(3):418-425. https://doi.org/10.1093/aje/kws554

7. Hartholt KA, van Beeck EF, Polinder S, van der Velde N, van Lieshout EM, Panneman MJ et al (2011) Societal consequences of falls in the older population: injuries, healthcare costs, and longterm reduced quality of life. J Trauma 71(3):748-753. https://doi. org/10.1097/TA.0b013e3181f6f5e5

8. DeGrauw X, Annest JL, Stevens JA, Xu L, Coronado V (2016) Unintentional injuries treated in hospital emergency departments among persons aged 65 years and older, United States, 20062011. J Safety Res 56:105-109. https://doi.org/10.1016/j.jsr.2015. 11.002

9. Factsheet Valongevallen $65+$. https://www.veiligheid.nl/valpr eventie/kennis-en-cijfers/cijfers. Accessed 14 Feb 2020

10. Muir SW, Berg K, Chesworth B, Klar N, Speechley M (2010) Quantifying the magnitude of risk for balance impairment on falls in community-dwelling older adults: a systematic review and meta-analysis. J Clin Epidemiol 63(4):389-406. https://doi. org/10.1016/j.jclinepi.2009.06.010

11. de Groot MH, van der Jagt-Willems HC, van Campen JP, Lems WF, Beijnen JH, Lamoth CJ (2014) A flexed posture in elderly patients is associated with impairments in postural control during walking. Gait Posture 39(2):767-772. https://doi.org/10.1016/j. gaitpost.2013.10.015

12. Katzman WB, Parimi N, Gladin A, Fan B, Wong SS, Mergenthaler $\mathrm{J}$ et al (2018) Reliability of sagittal vertical axis measurement and association with measures of age-related hyperkyphosis. J Phys Ther Sci 30(12):1417-1423. https://doi.org/10.1589/jpts.30.1417

13. Demarteau J, Jansen B, Van Keymolen B, Mets T, Bautmans I (2019) Trunk inclination and hip extension mobility, but not thoracic kyphosis angle, are related to 3D-accelerometry based gait alterations and increased fall-risk in older persons. Gait Posture 72:89-95. https://doi.org/10.1016/j.gaitpost.2019.05.027

14. Roghani T, Zavieh MK, Manshadi FD, King N, Katzman W (2016) Age-related hyperkyphosis: update of its potential causes and clinical impacts-narrative review. Aging Clin Exp Res. https:// doi.org/10.1007/s40520-016-0617-3
15. O'Brien K, Culham E, Pickles B (1997) Balance and skeletal alignment in a group of elderly female fallers and nonfallers. $\mathrm{J}$ Gerontol A Biol Sci Med Sci 52(4):B221-B226

16. Arnold CM, Busch AJ, Schachter CL, Harrison L, Olszynski W (2005) The relationship of intrinsic fall risk factors to a recent history of falling in older women with osteoporosis. J Orthop Sports Phys Ther 35(7):452-460. https://doi.org/10.2519/jospt. 2005.35.7.452

17. Kado DM, Huang MH, Nguyen CB, Barrett-Connor E, Greendale GA (2007) Hyperkyphotic posture and risk of injurious falls in older persons: the Rancho Bernardo Study. J Gerontol A Biol Sci Med Sci 62(6):652-657

18. Kasukawa Y, Miyakoshi N, Hongo M, Ishikawa Y, Noguchi H, Kamo K et al (2010) Relationships between falls, spinal curvature, spinal mobility and back extensor strength in elderly people. J Bone Miner Metab 28(1):82-87. https://doi.org/10.1007/ s00774-009-0107-1

19. Ishikawa Y, Miyakoshi N, Kasukawa Y, Hongo M, Shimada Y (2013) Spinal sagittal contour affecting falls: cut-off value of the lumbar spine for falls. Gait Posture 38(2):260-263. https://doi.org/ 10.1016/j.gaitpost.2012.11.024

20. van der Jagt-Willems HC, de Groot MH, van Campen JP, Lamoth CJ, Lems WF (2015) Associations between vertebral fractures, increased thoracic kyphosis, a flexed posture and falls in older adults: a prospective cohort study. BMC Geriatr 15:34. https:// doi.org/10.1186/s12877-015-0018-z

21. Tominaga R, Fukuma S, Yamazaki S, Sekiguchi M, Otani K, Kikuchi S et al (2016) Relationship between kyphotic posture and falls in community-dwelling men and women: the locomotive syndrome and health outcome in Aizu Cohort Study. Spine 41(15):1232-1238. https://doi.org/10.1097/brs.0000000000 001602

22. Goto NA, Koele MC, van Loon IN, Boereboom FTJ, Verhaar MC, Emmelot-Vonk MH et al (2019) Thoracic vertebral fractures and hyperkyphosis in elderly patients with end-stage kidney disease; do these patients have different clinical outcomes? Bone 127:181-187. https://doi.org/10.1016/j.bone.2019.06.007

23. McDaniels-Davidson C, Nichols JF, Vaida F, Marshall LM, Kado DM (2020) Kyphosis and 3-year fall risk in community-dwelling older men. Osteoporos Inter J Established Result Coop Eur Found Osteoporos Nat Osteoporos Found USA 31(6):1097-1104. https:// doi.org/10.1007/s00198-019-05155-8

24. Fon GT, Pitt MJ, Thies AC Jr (1980) Thoracic kyphosis: range in normal subjects. AJR Am J Roentgenol 134(5):979-983. https:// doi.org/10.2214/ajr.134.5.979

25. van Wijngaarden JP, Dhonukshe-Rutten RA, van Schoor NM, van der Velde N, Swart KM, Enneman AW et al (2011) Rationale and design of the B-PROOF study, a randomized controlled trial on the effect of supplemental intake of vitamin B12 and folic acid on fracture incidence. BMC Geriatr 11:80. https://doi.org/10.1186/ 1471-2318-11-80

26. van Wijngaarden JP, Swart KM, Enneman AW, Dhonukshe-Rutten RA, van Dijk SC, Ham AC et al (2014) Effect of daily vitamin B-12 and folic acid supplementation on fracture incidence in elderly individuals with an elevated plasma homocysteine concentration: B-PROOF, a randomized controlled trial. Am J Clin Nutr 100(6):1578-1586. https://doi.org/10.3945/ajcn.114.090043

27. Katzman WB, Harrison SL, Fink HA, Marshall LM, Orwoll E, Barrett-Connor E et al (2015) Physical function in older men with hyperkyphosis. J Gerontol A Biol Sci Med Sci 70(5):635-640. https://doi.org/10.1093/gerona/glu213

28. Katzman WB, Vittinghoff E, Kado DM, Lane NE, Ensrud KE, Shipp K (2016) Thoracic kyphosis and rate of incident vertebral fractures: the Fracture Intervention Trial. Osteoporos Inter 
J Established Result Coop Eur Found Osteoporos Nat Osteoporos Found USA 27(3):899-903. https://doi.org/10.1007/ s00198-015-3478-2

29. Lorbergs AL, Murabito JM, Jarraya M, Guermazi A, Allaire BT, Yang L et al (2017) Thoracic kyphosis and physical function: the Framingham Study. J Am Geriatr Soc 65(10):2257-2264. https:// doi.org/10.1111/jgs. 15038

30. McDaniels-Davidson C, Davis A, Wing D, Macera C, Lindsay SP, Schousboe JT et al (2017) Kyphosis and incident falls among community-dwelling older adults. Osteoporos Inter J Established Result Coop Eur Found Osteoporos Nat Osteoporos Found USA. https://doi.org/10.1007/s00198-017-4253-3

31. Watson SL, Weeks BK, Weis LJ, Harding AT, Horan SA, Beck BR (2019) High-intensity exercise did not cause vertebral fractures and improves thoracic kyphosis in postmenopausal women with low to very low bone mass: the LIFTMOR trial. Osteoporos Int J Established Result Coop Eur Found Osteoporos Nat Osteoporos Found USA 30(5):957-964. https://doi.org/10.1007/ s00198-018-04829-z

32. Tran TH, Wing D, Davis A, Bergstrom J, Schousboe JT, Nichols JF et al (2016) Correlations among four measures of thoracic kyphosis in older adults. Osteoporos Int J Established Result Coop Eur Found Osteoporos Nat Osteoporos Found USA 27(3):12551259. https://doi.org/10.1007/s00198-015-3368-7

33. Kado DM, Christianson L, Palermo L, Smith-Bindman R, Cummings SR, Greendale GA (2006) Comparing a supine radiologic versus standing clinical measurement of kyphosis in older women: the Fracture Intervention Trial. Spine 31(4):463-467. https://doi. org/10.1097/01.brs.0000200131.01313.a9

34. Lamb SE, Jorstad-Stein EC, Hauer K, Becker C (2005) Development of a common outcome data set for fall injury prevention trials: the Prevention of Falls Network Europe consensus. J Am Geriatr Soc 53(9):1618-1622. https://doi.org/10.1111/j.15325415.2005.53455.x

35. Swart KM, van Schoor NM, Heymans MW, Schaap LA, den Heijer M, Lips P (2013) Elevated homocysteine levels are associated with low muscle strength and functional limitations in older persons. J Nutr Health Aging 17(6):578-584. https://doi.org/10.1007/ s12603-013-0047-2

36. Carman DL, Browne RH, Birch JG (1990) Measurement of scoliosis and kyphosis radiographs. Intraobserver and interobserver variation. J Bone Joint Surg Am. 72(3):328-33

37. Stotts AK, Smith JT, Santora SD, Roach JW, D'Astous JL (2002) Measurement of spinal kyphosis: implications for the management of Scheuermann's kyphosis. Spine 27(19):2143-2146. https://doi. org/10.1097/01.brs.0000025709.33864.f8

38. Katzman WB, Vittinghoff E, Ensrud K, Black DM, Kado DM (2011) Increasing kyphosis predicts worsening mobility in older community-dwelling women: a prospective cohort study. J Am Geriatr Soc 59(1):96-100. https://doi.org/10.1111/j.1532-5415. 2010.03214.x

39. Kado DM, Miller-Martinez D, Lui LY, Cawthon P, Katzman WB, Hillier TA et al (2014) Hyperkyphosis, kyphosis progression, and risk of non-spine fractures in older community dwelling women: the study of osteoporotic fractures (SOF). J Bone Miner Res off J Am Soc Bone Miner Res 29(10):2210-2216. https://doi.org/10. 1002/jbmr.2251

40. Greig AM, Bennell KL, Briggs AM, Wark JD, Hodges PW (2007) Balance impairment is related to vertebral fracture rather than thoracic kyphosis in individuals with osteoporosis. Osteoporos int J Established Result Coop Eur Found Osteoporos Nat Osteoporos Found USA 18(4):543-551. https://doi.org/10.1007/ s00198-006-0277-9

41. Imagama S, Ito Z, Wakao N, Seki T, Hirano K, Muramoto A et al (2013) Influence of spinal sagittal alignment, body balance, muscle strength, and physical ability on falling of middle-aged and elderly males. Eur Spine J off Pub Eur Spine Soc Eur Spinal Deformity Soc Eur Sec Cervical Spine Res Soc 22(6):1346-1353. https://doi.org/10.1007/s00586-013-2721-9

42. Muramoto A, Imagama S, Ito Z, Hirano K, Ishiguro N, Hasegawa Y (2016) Spinal sagittal balance substantially influences locomotive syndrome and physical performance in community-living middle-aged and elderly women. J Orthop Sci 21(2):216-221. https://doi.org/10.1016/j.jos.2015.12.016

43. Ishikawa Y, Miyakoshi N, Hongo M, Kasukawa Y, Kudo D, Shimada Y (2017) Relationships among spinal mobility and sagittal alignment of spine and lower extremity to quality of life and risk of falls. Gait Posture 53:98-103. https://doi.org/10.1016/j.gaitp ost.2017.01.011

44. Katzman WB, Huang MH, Lane NE, Ensrud KE, Kado DM (2013) Kyphosis and decline in physical function over 15 years in older community-dwelling women: the Study of Osteoporotic Fractures. J Gerontol A Biol Sci Med Sci 68(8):976-983. https:// doi.org/10.1093/gerona/glt009

45. Katzman WB, Vittinghoff E, Lin F, Schafer A, Long RK, Wong $S$ et al (2017) Targeted spine strengthening exercise and posture training program to reduce hyperkyphosis in older adults: results from the study of hyperkyphosis, exercise, and function (SHEAF) randomized controlled trial. Osteoporos Int J Established Result Coop Eur Found Osteoporos Nat Osteoporos Foun USA 28(10):2831-2841. https://doi.org/10.1007/s00198-017-4109-х

Publisher's Note Springer Nature remains neutral with regard to jurisdictional claims in published maps and institutional affiliations. 